$\xi=-1$

\title{
Effect of Exercise Program on Fatigue and Depression among Geriatric Patients Undergoing Hemodialysis
}

\author{
Soad Hassan Abd Elhameed ${ }^{1}$, Doaa El Sayed Fadila ${ }^{2}$ \\ ${ }^{1}$ Assistant Professor of Gerontological Nursing, Faculty of Nursing, Mansoura University, Egypt \\ ${ }^{2}$ Lecturer of Gerontological Nursing, Faculty of Nursing, Mansoura University, Egypt \\ *Corresponding author E-mail: drsoadhassan@mans.edu.eg
}

\begin{abstract}
Background: Fatigue is one of the foremost common complications faced the hemodialysis elderly patients. Fatigue not only impact the daily lives and activities of patients but it conjointly influences their quality of life, which can afterwards result in magnified depression, tiny social interactions and increase dependency on others.

Aim: Determine the effect of exercise program on fatigue and depression among geriatric patients undergoing hemodialysis.

Design: Randomized controlled trial (pretest post-test) design was used.

Setting: The study was carried out in the dialysis units of Mansoura University Hospital and New Mansoura General Hospital.

Subjects: A purposive sample of 62 geriatric patients undergoing hemodialysis was selected and randomly allocated into two equal groups, study group $(\mathrm{n}=31)$ and control group $(\mathrm{n}=31)$.

Tools: Three tools were used; Structured interview questionnaire sheet, Multidimensional Fatigue Inventory Scale and Geriatric Depression Scale Short Form.

Results: The mean age of the study and control groups was $63.45 \pm 4.49$ and $64.7 \pm 5.25$ respectively. A high statistically significant change in fatigue and depression score (pre and post 2 months) between the study and the control groups was observed (P=0.000). Moreover, a statistically significant relation was observed between fatigue and age of the hemodialysis geriatric patients after implementation of the exercise program $(\mathrm{P}=0.002)$.

Conclusion: Implementation of the exercise program proved to be effective in improving the level of fatigue and depression among geriatric patients undergoing hemodialysis in the study group.

Recommendation: Encourage geriatric patients undergoing hemodialysis to perform regularly range of motion and relaxation exercises in order to alleviate fatigue and overcome depression.
\end{abstract}

Keywords: Depression; Exercise; Fatigue; Geriatric Patients; Hemodialysis.

\section{Introduction}

End stage renal disease (ESRD) is a serious irreversible progressive disorder and considered the last stage of chronic kidney disease (Huang et al., 2014; Lewis, 2015). The number of geriatric patients with ESRD is increasing around the world. The risk factors for this disease are aging of the population, increasing prevalence of hypertension and diabetes mellitus, and earlier recognition and referral for ESRD (Wold, 2012; Verberne, 2016). The estimated annual incidence of ESRD in Egypt is around 74 per million and the total prevalence of ESRD is 650 per million (Ahmed et al., 2010; Barsoum, 2013). Worldwide more than two million patients with ESRD have renal replacement therapy by either renal transplantation, peritoneal dialysis, or intermittent hemodialysis (HD) (Tordoir, Bode, \& Van Loon, 2015). For elderly people who advance to ESRD, hemodialysis is often a beneficial treatment option. While HD is a life-sustaining therapy and extends life, may also produce, increase or prolong suffering in selected subgroups of geriatric patients (Swidler, 2009).

The foremost common side effect of HD is fatigue and considered the most important nursing diagnosis in patients with chronic renal failure (Amini, Goudarzi, Masoudi, Ahmadi, \& Momeni, 2016). Fatigue is "a multidimensional, complex, and multifactorial phenomenon". Also, it has been defined as "extreme and persistent tiredness, weakness or exhaustion" (Artom, Moss-Morris, Caskey, \& Chilcot, 2014). Fatigue is affecting nearly $42-89 \%$ of end-stage chronic kidney disease patients and is notably linked with the existence of poor health status among patients undergoing hemodialysis (Picariello, Moss-Morris, McDougall, \& Chilcot, 2016). Moreover, individuals undergoing hemodialysis usually develop psychological problems. The most important of them is depression, because of its high prevalence, probable to lowering quality of life and increase mortality (Mauk, 2014; Robnett \& Chop, 2015). Depression prevalence in HD patients was $60.5 \%$. In spite of the detrimental consequences and high prevalence, depression is still a misdiagnosed disorder (Watnick, Kirwin, Mahnensmith, \& Concato, 2003). 
HD geriatric patients also experience a substantial symptoms burden that ends up with low quality of life. Moreover, management of fatigue and depression using pharmacological drugs are associated with side effects and are mainly costly. So, appropriate alternative treatments are important (Amini et al., 2016). The favorable approach for symptom management is exercise but the effect of exercise in HD patients on fatigue and depression is still undetermined (Song, Hu, Diao, Chen, \& Jiang, 2018). There are many disputations about the valuable effects of exercise during HD. Many researchers expect benefits of both exercise and dialysis via intradialytic exercise and mentioned that exercise has been determined as an important part of health improvement activities for patients undergoing hemodialysis (White \& Grenyer, 2006; Cho \& Sohng, 2014). Exercise programs with short term display varied results rely on the quality of life, level of fatigue, and the burden of disease. Fortunately, exercise training is valuable for patients undergoing hemodialysis, but the benefits vary depending on the willingness to participate and on the patient's abilities (Bulckaen et al., 2011).

Nurses predominantly have more contact with patients undergoing HD than other clinical staff and are in ideal situation for monitoring of clinical issues likely to affect patients on dialysis and to optimize assessment and management (Castner, 2011). In addition, the importance of exercise in improving the well-being of hemodialysis patients in general has emphasized in evidence from the published studies over years. However, few studies studied exercises in HD older patients, those carried out conveyed positive benefits similar to those seen in younger patients (Tao, Chow, \& Wong, 2015; Kontos et al., 2017). The elderly person is faced with many physiological and psychosocial changes which may affect their functional capacity and the health status. So, it is very important to research the effect of exercises on the geriatric patients undergoing hemodialysis. As well, the gerontological nurse has an important role in evaluating fatigue, depression and construct measures that directly decrease its impact on the elderly health.

\section{Aim of the study}

This study was conducted in order to determine the effect of exercise program on fatigue and depression among geriatric patients undergoing hemodialysis.

\section{Research hypothesis}

Geriatric patients undergoing hemodialysis involved in the exercise program (study group) will develop a significant reduction in fatigue and depression level after program implementation than those in control group.

\section{Method}

4.1. Study design: A randomized controlled trial (pretest post-test) design was used.

4.2. Setting: The study was carried out in the dialysis units of Mansoura University Hospital and New Mansoura General Hospital

\subsection{Subjects:}

A purposive sample of 62 geriatric patients undergoing hemodialysis, admitted to the above settings were randomly selected and allocated into two equal groups, study group $(n=31)$ and control group $(n=31)$ using day randomization technique. Systematic random sampling was used for data gathering. Homogeneity of both groups was established.

Initially a total of 120 geriatric patients undergoing hemodialysis were assessed for the study eligibility. Using inclusion and exclusion criteria, the eligible participants were 76 geriatric patients. The sample size was calculated using DSS sample calculator using the following parameters: Alpha error $=0.05$, Beta error $=0.20$, the first proportion $15 \%$ and the second proportion 45\% (Maniam et al., 2014; Soliman, 2015; Hassanpour \& Jalali, 2016). Based on these parameters the required sample size in the proposed study was 56 geriatric patients. The sample size was adjusted to 62 to account for anticipated withdrawal rate of $10 \%$.

Inclusion criteria included the following: (1) Aged 60 years and above; (2) Able to communicate; (3) Accept to participate in the study; (4) Had fatigue and depression (based on assessment); (5) Had no problems in arteriovenous fistulas; (6) No hospitalizations during the previous 3 months, except for vascular access repair; (7) No amputations or prostheses in lower extremities; (8) Able to ambulate and able to complete all study tests and program; and (9) Had no debilitating diseases as stroke, heart failure, coronary artery diseases, cognitive impairment and cancer that may interfere with prognosis or participation in the program.

\subsection{Tools: Three tools were used to collect the necessary data}

Tool I: Structured interview questionnaire sheet

This tool was developed by the researchers based on review of relevant literature. It consists of two parts: Part I: Sociodemographic characteristics of geriatric patients. It includes data such as; age, sex, level of education, marital status, occupation before retirement, monthly income, living condition and residence. Part II: Clinical history of geriatric patients. It includes data such as; causes of renal failure, onset of disease, starting hemodialysis, number of hemodialysis sessions, presence of comorbidities and compliance with drugs.

\section{Tool II: The Multidimensional Fatigue Inventory Scale (MFI-20)}

This tool was developed by Smet et al., (1995). It was used to measure the level of fatigue. The scale includes five subscales: general fatigue, mental fatigue, physical fatigue, reduced activity and reduced motivation. Every subscale consists of 4 items. The total scale items are 20 and has even proportion of positively and negatively worded items. The score achieved by five points likert scale (1- yes that is true through to $5-$ no, that is not true). The global fatigue score ranged from 20-100. The severity of fatigue was divided into 3 categories: score from 20 to 44 as mild fatigue, from 45 to 71 as moderate fatigue and from 72 to 100 as sever fatigue. High score indicates a high level of fatigue. 


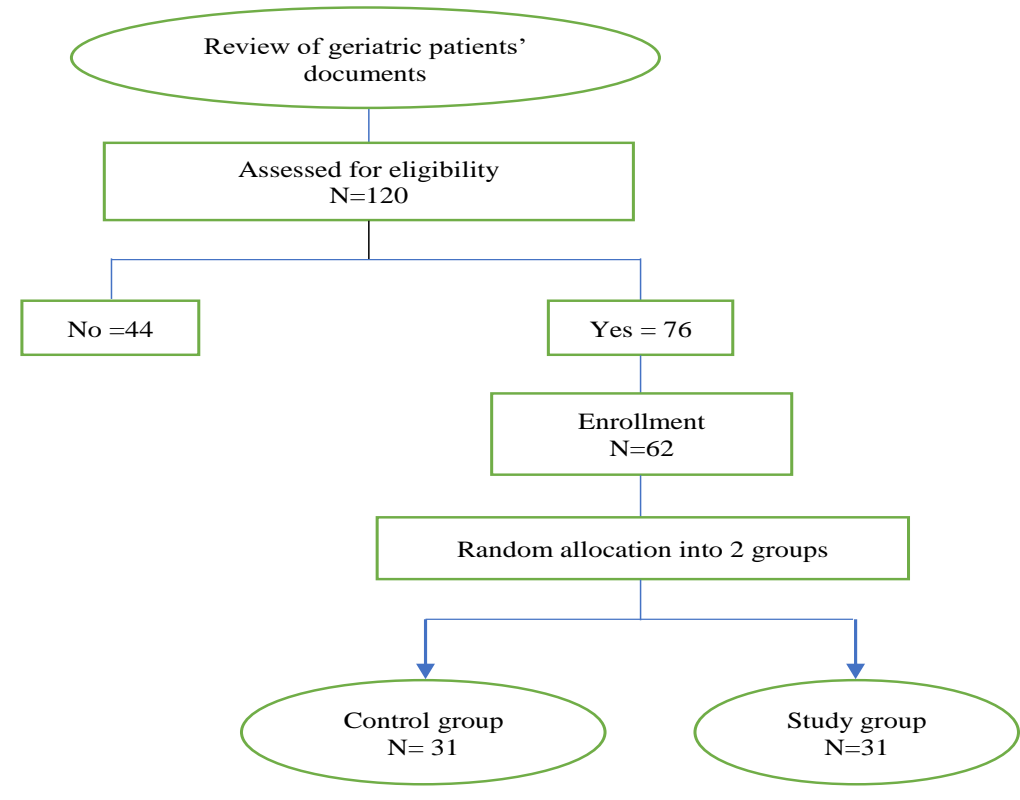

Fig. 1: Flowchart of the Participants Enrolled in the Study.

\section{Tool III: The Geriatric Depression Scale (GDS) Short Form (1986)}

This tool was developed by Sheikh \&Yesavage (1986). It was used to assess the presence of depression and general wellbeing of older adults. It was translated into Arabic and approved to be valid and reliable ( $\mathrm{r}=0.70)$ by Elhuseiny (2013). The scale includes fifteen questions. For ten (10) questions, a positive answer indicates the presence of depression and negative answer for the remaining five questions (question numbers 1, 5, 7, 11\&13) also indicates depression. When the response to a question is yes, a score of one is allotted when the response is no a score of zero is allotted. The older adult chooses the answer either yes: one (1) or No: zero (0) for how he/ she have felt over the last week. The total score for the tool is fifteen; items are summed for total score. As score from zero to 4 is assigned for those who have no depression, a score from 5 to 8 is assigned for those who have mild depression, and a score from 9 to 11 is assigned for those who have moderate depression and a score from 12 to 15 is assigned for those who have severe depression.

\subsection{Procedure}

1) Official letters were issued to Mansoura University and New Mansoura General Hospitals directors to obtain their approval and a written permission was taken to collect the necessary data.

2) Explanation of the study aim and nature was given to the nursing and medical staff in the dialysis units of both hospitals to obtain their cooperation.

3) Tool I (Structured interview questionnaire sheet) was developed by the researchers based on review of relevant literature.

4) Tool II (The Multidimensional Fatigue Inventory Scale) was translated into Arabic and tested for its content validity and reliability using test-retest method $(\mathrm{r}=0.88)$.

5) The Arabic version of tool III (Geriatric Depression Scale) was used. The reliability was assured by using spearman correlation coefficient $(r=0.96)$.

6) Tool II was tested for content validity by a jury of five experts in the related fields of the study. The necessary modifications were carried out accordingly.

7) A pilot study was carried out on $10 \%(n=7)$ of geriatric patients at Mansoura University Hospital from the hemodialysis unit to ascertain the clarity and applicability of the study tools. According to findings of the pilot study, the necessary modifications were done. Then, the tools were put into their final form. Those were excluded from the study sample.

8) Pretest using the study tools (tool II and III) was done before the exercise program implementation for the study subject in both groups to assess the level of fatigue and depression.

9) The control group was managed according to the usual hospital care.

10) Each patient in the study subjects received adequate description of the exercise program (technique), demonstration and redemonstration was done.

11) The developed exercise program was conducted on individual basis for the study group. The researchers visit the hemodialysis units for three days each week and implement the exercise program for 3 to 5 geriatric patients daily.

12) The exercise program was carried out in 24 session over two months. Every session took about 10 to 15 minutes (according to the required activities in every session to be achieved and the elder's attention span).

13) The exercise program starts half an hour after geriatric patients were connected to the dialysis machine.

14) The exercise program comprised two main parts namely: Range of motion exercise (ROM) and relaxation exercise. ROM exercises were given only to the study group alongside the routine care. ROM exercises practiced for 10/15 min/day, in the first 2 hours of dialysis, 3 times a week. The exercises were expanded in terms of strength and repetition with respect to the subjects' capabilities. ROM exercises was conducted to all joints of lower and upper limb, except body part connected to dialysis machine and give attention to other limb engaged in exercise to avoid disconnection. The geriatric patients were promoted to do flexibility and stretching movements (flexion and extension), start from 10- 15 rounds per minute (15 time) for the muscles of neck, arm, abdomen, thigh, and shin as well as in their wrist, elbow, shoulder, knee, spinal, and ankle joints. For the limb with fistula, the patient was instructed to close their eyes and imagine moving this part. 
15) The geriatric patients were instructed to do relaxation exercises during the exercise intervals under the researchers' guidance. They instructed to take a deep breath and were taught to do the next steps; stay in comfortable and stable position, close the eyes, calm down and relax the body (relax from toes to top of head), take a breath from nose, exhale from the mouth whenever exhaling, repeat one word or number, inhale, and exhale with comfort. Try to keep the body and muscles relaxed, then open the eyes slowly and do not move for few minutes. The geriatric patients were encouraged to do this for $10 \mathrm{~min}$ (10-15 time).

16) The ROM exercises should be stopped in cases of dyspnea, chest pain, nausea, vomiting, fainting, and muscle or joint pain.

17) The geriatrics safety was maintained during the implementation of the exercise program and safety tips was encouraged by the researchers before, during and after the exercise to be followed by the patient as well as the environment.

18) Posttest was done at the end of each month for both groups using study tools (tool II and III) to evaluate the effect of implemented exercise program on fatigue and depression level. Post-test 1 (after 1 month) and post-test 2 (after 2 months) from the implementation of the exercise program.

19) The researchers follow the strategies of teaching for geriatric patients by using clear, concise and simple language in presentation, large printed materials and a brief summary was given at the end of each session about the important point. Printed copy of the exercise program was given to the geriatric patients to attract their attention, motivate and support for teaching and practicing.

20) Sessions done by using presentation and discussion. Teaching materials included power point presentation using lab top, illustrated picture, and videos.

21) Time taken to complete the study tools with each geriatric patient ranged from 20-30 minutes.

22) Data collection took place between the mid of May 2018 and the end of November 2018.

\subsection{Ethical considerations}

The study protocol was approved by Faculty of Nursing Mansoura University Research Ethics Committee. Verbal informed consent was taken from geriatric patients who agreed to participate in the study after explanation of the study aim, benefits, risks, and procedures. The safety of geriatric patients was maintained throughout the study. Anonymity and privacy of the geriatric patients and confidentiality of the collected data were maintained. The right to withdraw at any time was assured.

\section{Statistical analysis}

Data was analyzed using PC with statistical package for social science (SPSS) version 16. The 0.05 and 0.01 levels were used as the cut off value for statistical significance. The following statistical measures were used; descriptive statistics (Count, percentage, mean, SD) and analytical statistics (chi square test, Independent t-test, paired sample t-test, ANOVA test of significance and Spearman's correlation coefficient). In the results ( $\mathrm{p})^{1}$ comparing before and after 1 month from the implementation of the exercise program, while (p) ${ }^{2}$ comparing before and 2 months after the implementation of the exercise program between the study and control groups.

\section{Results}

Table 1 illustrates that; the mean age of the study and control groups was $63.45 \pm 4.49$ and $64.7 \pm 5.25$; respectively. Males constituted $58.1 \%$ of subjects in the study group and $54.8 \%$ of subjects in the control group. Illiteracy was prevailing among $41.9 \%$ and $64.5 \%$ in the study and control group; respectively. $77.4 \%$ and $45.2 \%$ of the study and control groups respectively were married. Moreover, $61.3 \%$ and $58.1 \%$ of subjects in the study and control group reported working before retirement, and $67.7 \%$ and $51.6 \%$ reported having enough income, $87.1 \%$ and $74.2 \%$ of the geriatrics in the study and control group reported living with the family, and $51.6 \%$ and $74.2 \%$ of them residing in rural area; respectively. It was obvious from the table that no statistically significance difference is found between both groups regarding sociodemographic characteristics.

Concerning clinical data of hemodialysis geriatric patients, table 2 illustrates that hypertension was the cause of renal failure as mentioned by $54.8 \%$ of subjects in the study group and $48.4 \%$ of subjects in the control group. $93.5 \%$ and $96.8 \%$ of the hemodialysis geriatric patients in the study and control group respectively had renal failure since more than 1 year. $87.1 \%$ and $96.8 \%$ took a 3 -dialysis session per week in the study and control group respectively. For comorbidity, $54.8 \%$ in each group had one chronic disease. $67.7 \%$ and $71 \%$ of the patients in the study and control group reported compliance with medication. A statistically significant difference was found regarding start of hemodialysis between the two group $\left(\mathrm{P}=0.008^{*}\right)$.

Table 3 shows a high statistically significant change in fatigue score pre and post 2 months of program implementation between both groups $(\mathrm{P}=0.000)$. For the study group, $38.7 \%$ had mild level of fatigue, $51.6 \%$ had moderate level of fatigue, and $9.7 \%$ had severe level of fatigue in the pretest. While, post 2 months of the exercise program implementation, $90.3 \%$ had mild fatigue. For the control group, the hemodialysis geriatric patients experience the worst change in the level of fatigue (high score of fatigue). In the pretest, $67.7 \%$ had mild level of fatigue, $25.8 \%$ had moderate level of fatigue, and $6.5 \%$ had severe level of fatigue. While post 2 months, the level of fatigue changed to be $51.6 \%$ (moderate fatigue level) and $9.7 \%$ (severe fatigue level).

Table 4 represents that, there was a high statistically significant changes in depression score pre and post 2 months between both groups $(\mathrm{P}=0.000)$. In the study group, during pretest $58.1 \%$ of them had mild level of depression, $29 \%$ had moderate level of depression, $12.9 \%$ had sever level of depression and post 2 months of the exercise program $61.3 \%$ of them had no depression. For the control group, the hemodialysis geriatric patients experience the worst change in the level of depression (high score of depression). As in pretest, $64.5 \%$ had mild level of depression, $25.8 \%$ had moderate level of depression, and 9.7\% had severe level of depression. While post 2 months, the level of depression changed to be $29 \%$ (moderate depression) and $16.1 \%$ (severe depression).

The relation between mean total score of fatigue pre and post the implementation of exercise program in the study and control group are shown in table 5. The fatigue pretest mean score in the study group was 52.54 and 36.35 post 2 months. The difference was statistically significant $(\mathrm{P}=0.000)$. This displayed that, the patient in the study group had felt reduced in fatigue level at the end of 2 months of practicing exercises. Such difference was not detected in the control group. Moreover, there was a statistically significant change in fatigue score pre and post 2 months between the two group $(\mathrm{P}=0.000)$ (Figure 2). 
The relation between mean total score of depression pre and post the implementation of exercise program in the study and control group are shown in table 6. The study group depression pretest mean score was 8.26 and 4.9 post 2 months. The difference was statistically significant $(\mathrm{P}=0.000)$. This represent that, the patient in the study group had felt reduction in depression level at the end of 2 months of practicing exercises. Such difference was not detected in the control group. In addition, a statistically significant change in depression score pre and post 2 months between the two group $(\mathrm{P}=0.000)$ was observed (Figure 3).

Table 7 showed that, a statistically significant relation was observed between fatigue and age of the hemodialysis geriatric patients $(\mathrm{P}=$ $0.002 *)$ as well as the occupation before retirement $(\mathrm{P}=0.017 *)$ post 2 months of implementation of the exercise program in the study group. Moreover, no statistically significant relation was observed between depression and sociodemographic characteristics in both groups.

Table 1: Sociodemographic Characteristics of the Hemodialysis Geriatric Patients in Both Groups (N=62)

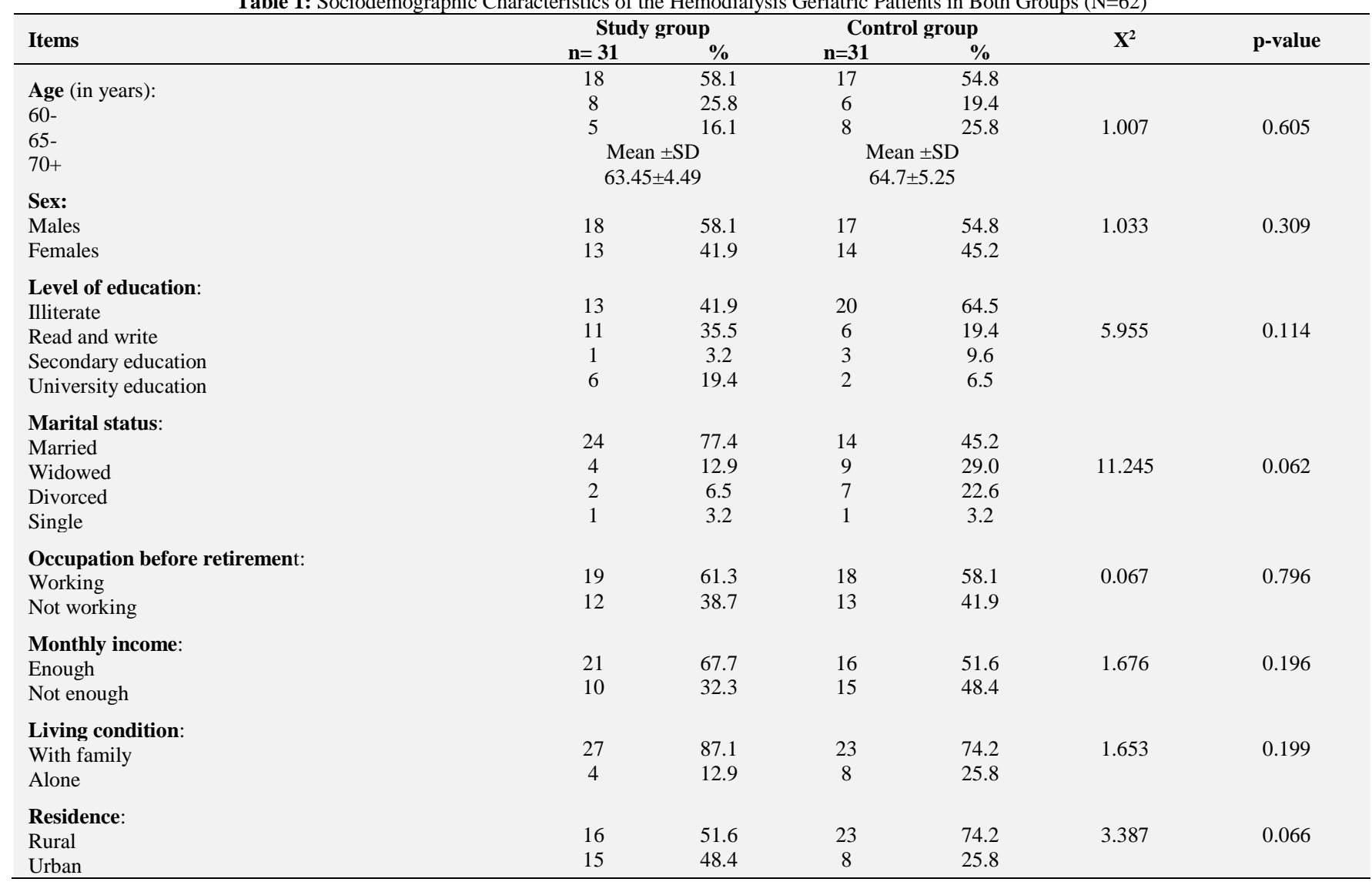

Table 2: Clinical Data of the Hemodialysis Geriatric Patients in Both Groups $(N=62)$

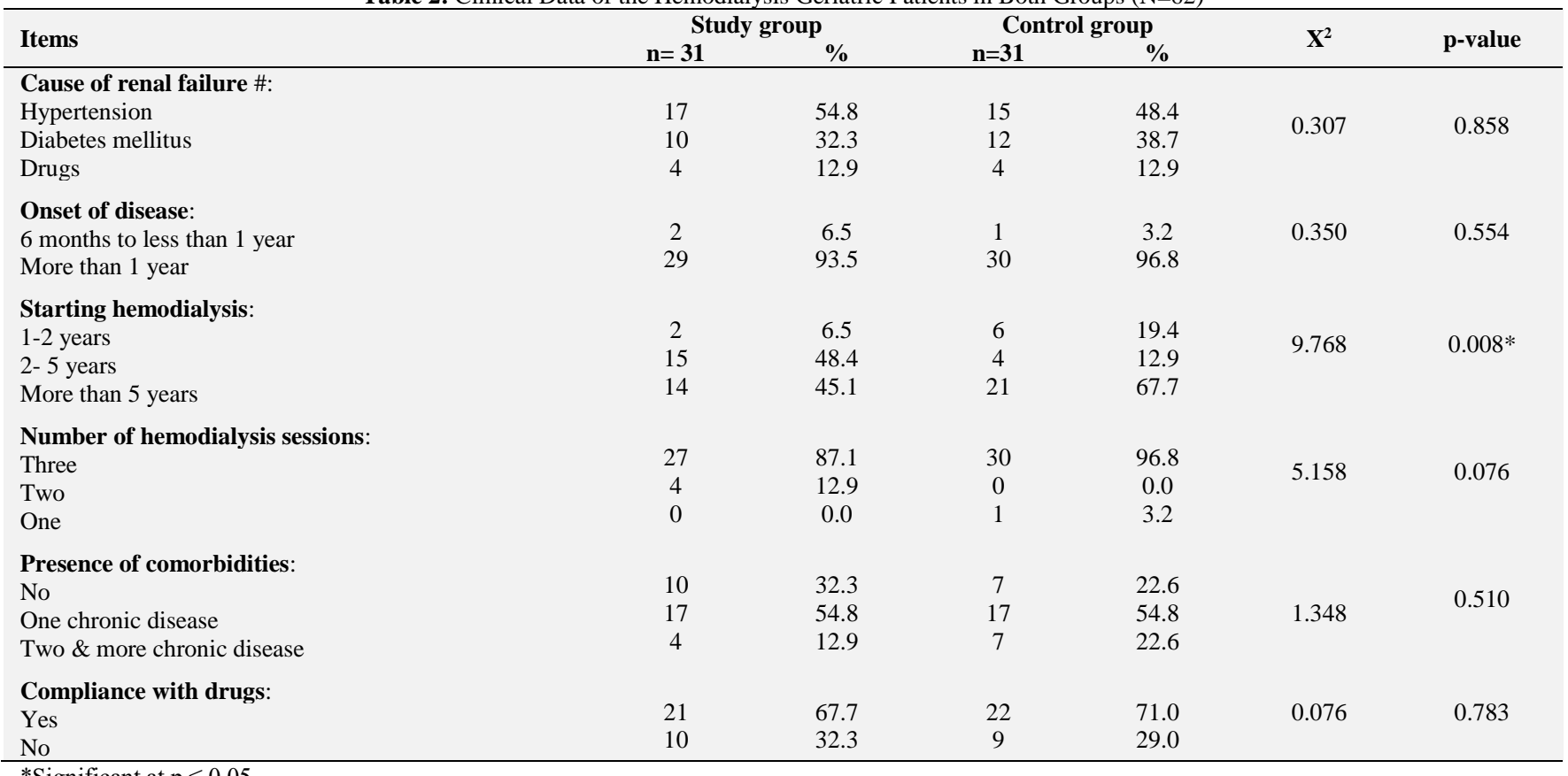

*Significant at $\mathrm{p} \leq 0.05$. 
Table 3: Distribution of Hemodialysis Geriatric Patients According to the Level of Fatigue Pre and Post the Program (N=62)

\begin{tabular}{|c|c|c|c|c|c|c|}
\hline \multirow[b]{2}{*}{ Items } & \multicolumn{2}{|c|}{ Study group } & \multicolumn{2}{|c|}{ Control group } & \multirow{2}{*}{$\mathbf{X}^{2}$} & \multirow{2}{*}{ p-value } \\
\hline & $n=31$ & $\%$ & $\mathrm{n}=\mathbf{3 1}$ & $\%$ & & \\
\hline \multicolumn{7}{|l|}{ Fatigue pre: } \\
\hline Mild & 12 & 38.7 & 21 & 67.7 & \multirow{3}{*}{5.321} & \multirow{3}{*}{0.070} \\
\hline Moderate & 16 & 51.6 & 8 & 25.8 & & \\
\hline Severe & 3 & 9.7 & 2 & 6.5 & & \\
\hline \multicolumn{7}{|l|}{ Fatigue post 1: } \\
\hline Mild & 23 & 74.2 & 13 & 41.9 & \multirow{3}{*}{7.444} & \multirow{3}{*}{$0.024^{*}$} \\
\hline Moderate & 8 & 25.8 & 16 & 51.6 & & \\
\hline Severe & 0 & 0.0 & 2 & 6.5 & & \\
\hline \multicolumn{7}{|l|}{ Fatigue post 2: } \\
\hline Mild & 28 & 90.3 & 12 & 38.7 & \multirow{3}{*}{18.295} & \multirow{3}{*}{$0.000 * *$} \\
\hline Moderate & 3 & 9.7 & 16 & 51.6 & & \\
\hline Severe & 0 & 0.0 & 3 & 9.7 & & \\
\hline
\end{tabular}

Post 1: Posttest after 1 month of the exercise program implementation.

Post 2: Posttest after 2 months of the exercise program implementation.

*Significant at $\mathrm{p} \leq 0.05$

Table 4: Distribution of Hemodialysis Geriatric Patients According to the Level of Depression Pre and Post the Program (N=62)

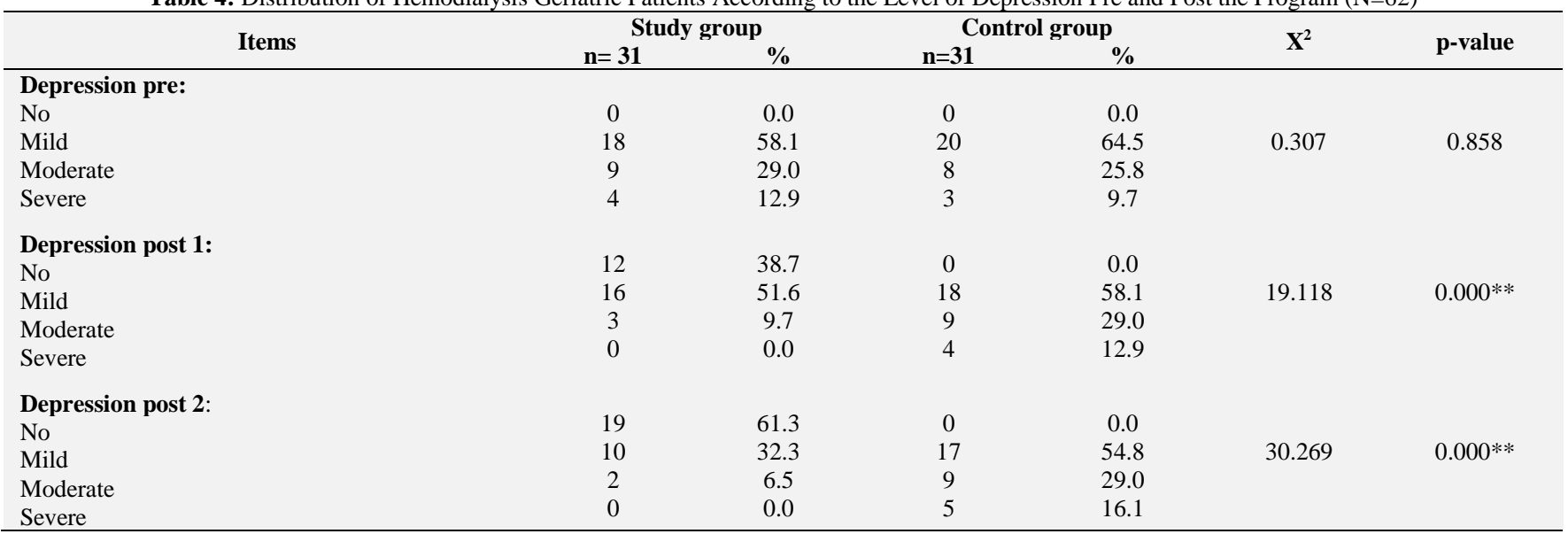

Post 1: Posttest after 1 month of the exercise program implementation.

Post 2: Posttest after 2 months of the exercise program implementation.

*Significant at $\mathrm{p} \leq 0.05$

Table 5: Relation between Total Fatigue Mean Score of Hemodialysis Geriatric Patients in Both Groups (N=62)

\begin{tabular}{|c|c|c|c|c|c|}
\hline \multirow[t]{2}{*}{ Items } & Fatigue pre & $\begin{array}{c}\text { Fatigue } \\
\text { post } 1 \text { month }\end{array}$ & $\begin{array}{c}\text { Fatigue } \\
\text { post } 2 \text { months }\end{array}$ & t-test $(p)^{1}$ & t-test $(p)^{2}$ \\
\hline & Mean \pm SD & Mean $\pm \mathrm{SD}$ & Mean \pm SD & & \\
\hline Study group $(n=31)$ & $52.54 \pm 11.82$ & $40.23 \pm 14.84$ & $36.35 \pm 8.84$ & $3.787(0.001)^{*}$ & $6.886(0.000)^{*}$ \\
\hline Control group $(n=31)$ & $47.84 \pm 11.76$ & $48.39 \pm 11.80$ & $50.90 \pm 12.17$ & $0.210(0.835)$ & $1.323(0.196)$ \\
\hline P value (between groups) & $1.572(0.121)$ & $2.397(0.020)^{*}$ & $5.384(0.000)^{*}$ & & \\
\hline
\end{tabular}

$(\mathrm{P})^{1}$ : comparing preprogram and 1 month after in each group

$(\mathrm{P})^{2}$ : comparing preprogram and 2 months after in each group

*Significant at $\mathrm{p} \leq 0.05$

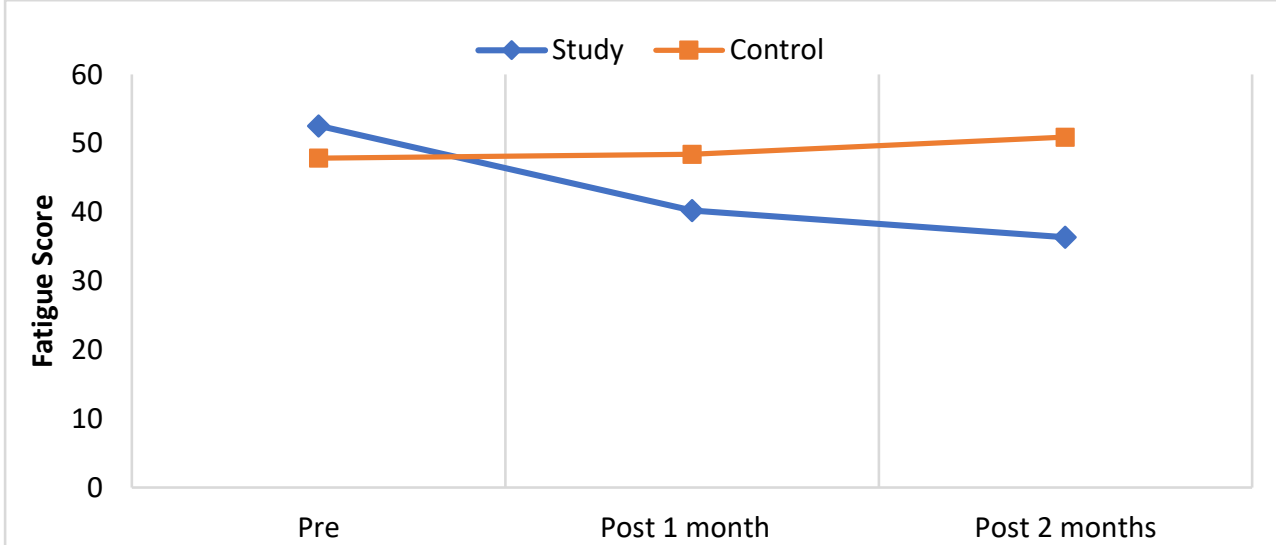

Fig. 2: Fatigue Score Changes in both Groups Pre and Post Program Implementation. 
Table 6: Relation between Total Depression Mean Score of Hemodialysis Geriatric Patients in Both Groups (N=62)

\begin{tabular}{|c|c|c|c|c|c|}
\hline Items & $\begin{array}{c}\text { Depression pre } \\
\text { Mean } \pm \text { SD }\end{array}$ & $\begin{array}{c}\text { Depression } \\
\text { post } 1 \text { month } \\
\text { Mean } \pm \text { SD }\end{array}$ & $\begin{array}{c}\text { Depression } \\
\text { post } 2 \text { months } \\
\text { Mean } \pm \text { SD }\end{array}$ & t-test $(p)^{1}$ & t-test $(\mathbf{p})^{2}$ \\
\hline Study group $\left(\mathrm{n}_{=} 31\right)$ & $8.26 \pm 2.58$ & $6.03 \pm 2.73$ & $4.90 \pm 2.26$ & $3.503(0.001) *$ & $6.508(0.000) *$ \\
\hline Control group $\left(\mathrm{n}_{=} 31\right)$ & $8.0 \pm 2.53$ & $8.29 \pm 2.22$ & $8.65 \pm 2.29$ & $1.393(0.174)$ & $1.693(0.101)$ \\
\hline $\mathrm{P}$ value (between groups) & $0.398(0.692)$ & $3.573(0.001)^{*}$ & $6.483(0.000)^{*}$ & & \\
\hline
\end{tabular}

$(\mathrm{P})^{1}$ : comparing preprogram and 1 month after in each group

$(\mathrm{P})^{2}$ : comparing preprogram and 2 months after in each group

*Significant at $\mathrm{p} \leq 0.05$

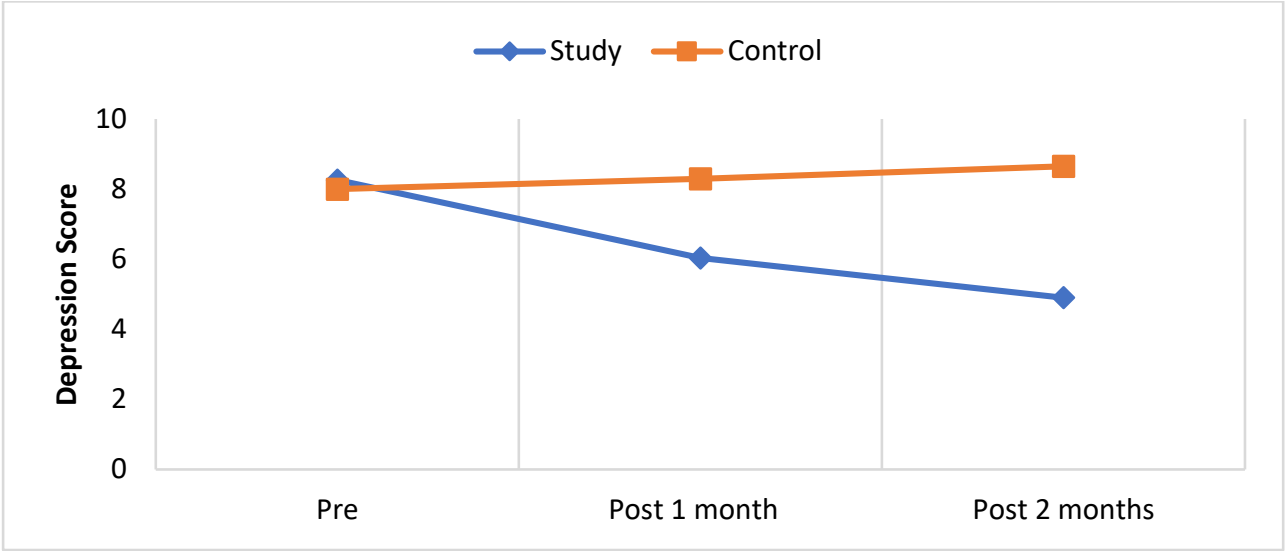

Fig. 3: Depression Score Changes in both Groups Pre and Post Program Implementation.

Table 7: Relation between Hemodialysis Geriatric Patients' Sociodemographic Characteristics, Mean of Fatigue, and Mean of Depression Post 2 Months of Exercise Program Implementation $(\mathrm{N}=62)$

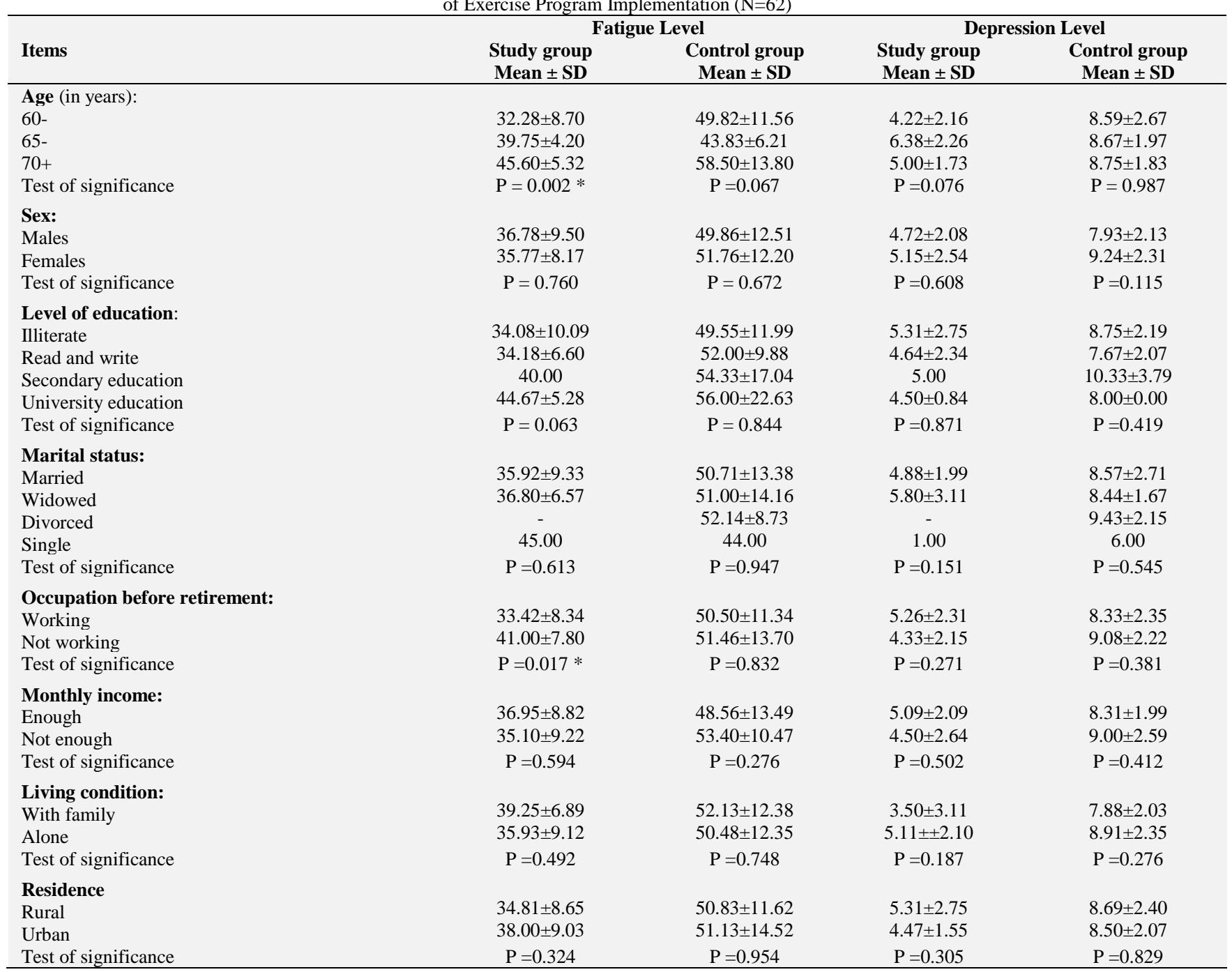

*Significant at $\mathrm{p} \leq 0.05$. 


\section{Discussion}

The increase of geriatric patients undergoing hemodialysis number and the duration of HD treatment repoint to the increasing importance of systematic exercise programs for hemodialysis patients (Cho \& Sohng, 2014). In spite of the positive impact reported on improving and maintaining patients' physical functions, exercise programs for patients undergoing HD are not a part of the typical care plan until now (Cruz et al., 2011). The standard management of end stage renal disease is either dialysis or kidney transplantation (Motedayen, Nehrir, Tayebi, Ebadi, \& Einollahi, 2014). Therefore, various exercise programs, such as range of motion exercises and relaxation exercises have been developed for patients undergoing hemodialysis to manage the mental and physical disorders due to chronic diseases have attracted the researcher's attention (EL Shemy, Elkazeh, \& ELkually, 2016). So, this study was carried to determine the effect of exercise program on fatigue and depression among geriatric patients undergoing hemodialysis.

Finding of the present study showed that mean age of the geriatric patients was 63 years in the study group and 64 years in the control group. These findings are in line with a study done in Egypt by Abd-Rabouh et al., (2017). While, Mahmoud et al., (2018) mentioned that, the mean age of the hemodialysis geriatric patients was 65 years. These results of increasing mean age of end stage renal disease patients reverberate the universal trends of dialysis patients living longer due to improving health care systems and safety standards performed in the dialysis units.

Fatigue was reported as the most prominent clinical symptom in patients with chronic kidney disease (Abd-Rabouh et al., 2017). Also, patients undergoing hemodialysis experience many symptoms, among which, the prevalence of fatigue is recorded to be high, with about 73.7-91\% of the patients experiencing this symptom (Yong et al., 2009; Gordon, Doyle, \& Johansen, 2011). A study was done by Horrigan et al., (2012) in USA, revealed that, all patients on long term hemodialysis suffer from fatigue. In addition, Soliman (2015) in Egypt mentioned that, 100\% of the studied sample experienced fatigue. From these results, it is evident that fatigue is common in geriatric patients undergoing hemodialysis and the emphasis on and attention to this symptom is needed on the part of healthcare providers especially nurses. For that, nurses should conserve the geriatric patients' energy when caring for them and help them in regulating the usage of their energy.

The present study showed a significant change in fatigue score pre and post the implementation of the exercise program in the study group and between both groups. These findings are consistent with the result of Chang et al., (2010) in Taiwan and study done in Iran by Motedayen et al., (2014), who reported a significant decrease in fatigue level after performing intradialytic exercise. According to the study done by El Shemy et al., (2016) in Egypt, training exercise during dialysis treatment represented improvement in all domain of the Multidimensional Fatigue Inventory. Moreover, the result of this study contradicts that of Amini et al., (2016) in Iran, who reported no significant effect of exercises on patient fatigue. While, the implementation of exercise program in this study proved to be beneficial for hemodialysis geriatric patients.

Depression is emerged by the year 2020 to be the main contributor to health care costs and the major cause of disease burden associated with older people (Turkmen et al., 2012). Despite the high prevalence and harmful consequences, depression is still a misdiagnosed disorder because of the superposed symptoms related to uremia (anorexia, fatigue, sleep disorders) and the absence of a systematic psychiatric evaluation (Watnick et al., 2003). Antidepressant are frequently prescribed, but negative side effect and drug interactions of antidepressants are of attention (Yaghmayi, Khalfi, Khost, \& Alavi, 2005). Moreover, a study done in USA by Finkelstein et al., (2008) mentioned that, mental health needs, especially debilitating levels of clinical depression and depressed mood, are common among patients undergoing dialysis.

The present study showed a significant change in depression score pre and post the implementation of the exercise program among the study group and between both groups. The difference is statistically significant. These findings may be related to the greatest acceptance of exercise training by the geriatric dialysis patients. Perhaps this is because the exercise training itself, which was conducted in safe and comfortable positions for the geriatrics and also, it did not require special concentration or any concern that it is being performed improperly. This come in accordance with the result of Reid et al., (2010) in USA reported that, exercises were linked with reduced depression symptoms and fostered the elderly quality of life. Also, finding of the present study indicates that muscle relaxation exercises affects the hemodialysis geriatric patient's mental health status. As well, this therapeutic approach proved to be effective in decreasing the study subjects' level of depression. So, it is important to focus on managing this disorder to facilitate and maintain the health of the geriatric patients, help them to cope better with the current health status and being satisfied with their life.

Regarding the relation between hemodialysis geriatric patients' sociodemographic characteristics, mean of fatigue, and mean of depression after 2 months of the exercise program in both groups. The current study showed a statistically significant relation between level of fatigue and patients age among the study group after implementation of the exercise program. This result may be related to the decreased organ function and physical strength associated with aging which may cause a patient to feel tired. This result supports those of Akin et al., (2014) and contradicts those of Abd-Rabouh et al., (2017) who stated that no significant relation between age and fatigue. Additionally, the present study has determined that no statistically significant relation was found between marital status and fatigue but married elderly had a lower level of fatigue than others. These findings may be related to the fact that patients who have a spouse receive assistance in daily activities, while widowers, single or divorced would either have to take care of the daily activities themselves or looking for help from others, meaning that breaks are less likely to happen in times of fatigue.

The present study showed no significant relation between geriatric patients' level of fatigue and sex. The findings represented that, severity and incidence of fatigue in males occurs more than female. This result may be justified by presence of other predisposing risk factors as high blood pressure and smoking which are common among male and may contribute to complicate their health status more than females. This result supports those of Chang et al., (2010). A study done in Turkey by Karadage et al., (2013) contradicts the findings of the present study and indicated that, women reveal significantly higher levels of fatigue than men. In addition, no significant relation was found between fatigue level and marital status of the hemodialysis geriatric patients in this study. This result supports those of Soliman (2015). Moreover, the present study showed a significant relation between fatigue level and occupation before retirement. As no working elderly reported high level of fatigue than worked elderly. This result may be justified by, unemployed elderly may state a higher level of fatigue than other because staying at home can lower the level of activity. This result supports those of Bai et al., (2015) in Taiwan and contradicts those of Abd-Rabouh et al., (2017) who reported no significant relation between work and fatigue. 
According to the results of this study the study hypothesis was accepted and proved. As the hemodialysis geriatric patients involved in the study group showed a significant reduction in the level of fatigue and depression after the implementation of the exercise program than those in the control group. Therefore, the research study can be considered as the start point and initiation of provision of exercise training and practices for hemodialysis geriatric patients. Moreover, nurses have an important role in teaching, helping, motivating, and assisting the patients to participate in the exercise program. This can be achieved by emphasizing the benefits in terms of increasing and maintaining functional abilities, improving strength and flexibility, decreasing fatigue and depression level and at the end improves the older adults' health.

\section{Conclusion}

In this study the implementation of the exercise program which consisted of range of motion exercises and muscle relaxation exercises proved to be effective in improving the level of fatigue and depression among the majority of geriatric patients undergoing hemodialysis in the study group. Moreover, range of motion and relaxation exercises used in this study are inexpensive and accessible treatments and could be beneficial for hemodialysis geriatric patients.

\section{Recommendations}

1) Encourage geriatric patients undergoing hemodialysis to perform regularly range of motion and relaxation exercises in order to alleviate fatigue and overcome depression.

2) Training courses on relaxation exercises can be periodically organized by dialysis centers for their geriatric patients undergoing hemodialysis to promote psychological adaptation.

3) Development and implementation of exercise programs for nurses to help them in caring for hemodialysis patients in order to decrease fatigue, depression and improve the older adult's health status.

\section{Acknowledgment}

We would like to state our deepest gratitude to the all hospital's directors, hemodialysis departments nurses, and the study participants for their collaboration in completion of this work.

\section{References}

[1] Huang Y., Cai X., Zhang J., Mai W., Wang S., Hu Y., Ren H., \& Xu D. (2014). Prehypertension and Incidence of ESRD: A Systematic Review and Meta-analysis. American Journal of Kidney Disease, 63(1),76-83. https://doi.org/10.1053/j.ajkd.2013.07.024.

[2] Lewis, S. L., Dirksen, S. R., Heitkemper, M. M., Bucher, L., \& Camera, I. (2015). Medical-Surgical Nursing-E-Book: Assessment and Management of Clinical Problems, Single Volume. $8^{\text {th }}$ ed. United States of America: Elsevier Health Sciences; 1170-4.

[3] Wold, G. H. (2012). Basic Geriatric Nursing. $5^{\text {th }}$ ed., St. louis, Mosby, Inc. affiliated to Elsevier Inc., 56.

[4] Verberne, W. R., Geers, A. T., Jellema, W. T., Vincent, H. H., van Delden, J. J., \& Bos, W. J. W. (2016). Comparative survival among older adults with advanced kidney disease managed conservatively versus with dialysis. Clinical Journal of the American Society of Nephrology, 11(4), 633640. https://doi.org/10.2215/CJN.07510715.

[5] Ahmed, A., Allam, M., Habil, E., Metwally, A., Ibrahiem, N., Radwan, M., El Gaafary, M., Afifi, A., Gadallah, M. (2010). Development of practice guidelines for hemodialysis in Egypt. Indian Journal of Nephrology, 20(4), 193. Retrieved from http://www.ncbi.nlm.nih.gov. https://doi.org/10.4103/0971-4065.73450.

[6] Barsoum, R. S. (2013). Burden of chronic kidney disease: North Africa. Kidney International Supplements, 3(2), 164-166. https://doi.org/10.1038/kisup.2013.5.

[7] Tordoir, J. H. M., Bode, A. S., \& Van Loon, M. M. (2015). Preferred strategy for hemodialysis access creation in geriatric patients. European Journal of Vascular and Endovascular Surgery, 49(6), 738-743. https://doi.org/10.1016/j.ejvs.2015.02.006.

[8] Swidler, M. A. (2009). Chapter 37: Dialysis Decisions in the Elderly Patient with Advanced CKD and the Role of Nondialytic Therapy. Retrieved from https://www.semanticscholar.org

[9] Amini, E., Goudarzi, I., Masoudi, R., Ahmadi, A., \& Momeni, A. (2016). Effect of progressive muscle relaxation and aerobic exercise on anxiety, sleep quality, and fatigue in patients with chronic renal failure undergoing hemodialysis. International Journal of Pharmaceutical and Clinical Research, 8(12), 1634-9. $\quad$ Retrieved $\quad$ from $\quad$ https://www.scopus.com/record/display.uri?eid=2-s2.085018211435\&origin=inward\&txGid=f92b804cdff579deb6b69138d6d2aeae

[10] Artom, M., Moss-Morris, R., Caskey, F., \& Chilcot, J. (2014). Fatigue in advanced kidney disease. Kidney International, 86(3), 497-505. https://doi.org/10.1038/ki.2014.86.

[11] Picariello, F., Moss-Morris, R., McDougall, I. C., \& Chilcot, A. J. (2016). The role of psychological factors in fatigue among end-stage kidney disease patients: a critical review. Clinical Kidney Journal, 10(1), 79-88. https://doi.org/10.1093/ckj/sfw113.

[12] Mauk, K. L. (2014). Gerontological nursing: Competencies for care. $3^{\text {rd }}$. ed., Jones \& Bartlett Publishers, $529-31$.

[13] Robnett, R. H., \& Chop, W. C. (2015). Gerontology for the health care professional. $3^{\text {rd }}$ ed., USA; Jones \& Bartlett Publishers, 124-5.

[14] Watnick, S., Kirwin, P., Mahnensmith, R., \& Concato, J. (2003). The prevalence and treatment of depression among patients starting dialysis. American Journal of Kidney Diseases, 41(1), 105-110. https://doi.org/10.1053/ajkd.2003.50029.

[15] Song, Y. Y., Hu, R. J., Diao, Y. S., Chen, L., \& Jiang, X. L. (2018). Effects of exercise training on restless legs syndrome, depression, sleep quality, and fatigue among hemodialysis patients: A systematic review and meta-analysis. Journal of Pain and Symptom Management, 55(4), 1184-95. https://doi.org/10.1016/j.jpainsymman.2017.12.472.

[16] White, Y. \& Grenyer, B. F. S. (2006). Do we encourage health or illness? A survey of exercise rehabilitation practices for patients in Australian renal units. Renal Society of Australasia Journal, 2 (1), 5-15. Retrieved from https://ro.uow.edu.au/hbspapers/1571/

[17] Cho, H., \& Sohng, K. Y. (2014). The effect of a virtual reality exercise program on physical fitness, body composition, and fatigue in hemodialysis patients. Journal of Physical Therapy Science, 26(10), 1661-5. http://creativecommons.org/licenses/by-nc-nd/3.0/. https://doi.org/10.1589/jpts.26.1661.

[18] Bulckaen, M., Capitanini, A., Lange, S., Caciula, A., Giuntoli, F., \& Cupisti, A. (2011). Implementation of exercise training programs in a hemodialysis unit: effects on physical performance. Journal of Nephrology, 24(6), 790. https://doi.org/10.5301/JN.2011.6386.

[19] Castner, D. (2011): Management of patients on hemodialysis before, during, and after hospitalization: challenges and suggestions for improvements. Nephrology Nursing Journal, 38(4), 319-320. Retrieved from https://www.therenalnetwork.org.

[20] Tao, X., Chow, S. K. Y., \& Wong, F. K. Y. (2015). A nurse-led case management program on home exercise training for hemodialysis patients: A randomized controlled trial. International Journal of Nursing Studies, 52(6), 1029-41. https://doi.org/10.1016/j.ijnurstu.2015.03.013. 
[21] Kontos, P., Alibhai, S. M., Miller, K. L., Brooks, D., Colobong, R., Parsons, T., \& Naglie, G. (2017). A prospective 2-site parallel intervention trial of a research-based film to increase exercise amongst older hemodialysis patients. BMC Nephrology, 18(1), 37. https://doi.org/10.1186/s12882017-0454-4.

[22] Maniam, R., Subramanian, P., Singh, S. K. S., Lim, S. K., Chinna, K., \& Rosli, R. (2014). Preliminary study of an exercise programme for reducing fatigue and improving sleep among long-term hemodialysis patients. Singapore Medical Journal, 55(9), 476. https://doi.org/10.11622/smedj.2014119.

[23] Soliman, H. (2015). Effect of intradialytic exercise on fatigue, electrolytes level and blood pressure in hemodialysis patients: A randomized controlled trial. Journal of Nursing Education \& Practice, 5(11), 16-28. https://doi.org/10.5430/jnep.v5n11p16.

[24] Hassanpour-Dehkordi, A., \& Jalali, A. (2016). Effect of progressive muscle relaxation on the fatigue and quality of life among Iranian aging persons. Acta Medica Iranica, 54(7), 430-436. Retrieved from http://acta.tums.ac.ir/index.php/acta/article/view/5009.

[25] Smets, E. M. A., Garssen, B., Bonke, B. D., \& De Haes, J. C. J. M. (1995). The Multidimensional Fatigue Inventory (MFI) psychometric qualities of an instrument to assess fatigue. Journal of Psychosomatic Research, 39(3), 315-325. https://doi.org/10.1016/0022-3999(94)00125-O.

[26] Sheikh, J. I., \& Yesavage, J. A. (1986). Geriatric Depression Scale (GDS): Recent evidence and development of a shorter version. Clinical Gerontologist: The Journal of Aging and Mental Health, 5(1-2), 165-173. https://doi.org/10.1300/J018v05n01_09.

[27] El Elhuseiny, S. (2013). Effect of Self Care Interventions on the Quality of Life of Older Adults with Heart Failure. Published Doctorate Thesis, University of Alexandria, Faculty of Nursing. Retrieved from http://library.mans.edu.eg/eulc_v5/Libraries/.

[28] Cruz, M. C., Andrade, C., Urrutia, M., Draibe, S., Nogueira-Martins, L. A., \& Sesso, R. D. C. C. (2011). Quality of life in patients with chronic kidney disease. Clinics, 66(6), 991-995. https://doi.org/10.1590/S1807-59322011000600012.

[29] Motedayen, Z., Nehrir, B., Tayebi, A., Ebadi, A., \& Einollahi, B. (2014). The effect of the physical and mental exercises during hemodialysis on fatigue: a controlled clinical trial. Nephro-Urology Monthly, 6(4). https://doi.org/10.5812/numonthly.14686.

[30] EL Shemy, M., Elkazeh, E., ELkually, R. (2016). Efficacy of Exercise Program in Intra Hemodialysis On patients 'Quality of Life. IOSR Journal of Nursing and Health Science, 5(1), 17-30.

[31] Abd-Rabouh, M., Abd Elhameed, S., Shebl, A. (2017). Relationship Between Fatigue and Functional Status of the Elderly Patients on Hemodialysis. Mansoura Nursing Journal, 4(2), 83-96. Retrieved from http://library.mans.edu.eg/eulc_v5/Libraries/.

[32] Mahmoud, M., Hassan, N., Abd Elhameed, S., Shebl, A. (2018). Relationship Between Pruritus and Quality of Life of Elderly Patients Undergoing Hemodialysis. IOSR Journal of Nursing and Health Science, 7(3):73-82.

[33] Yong, D. S. P., Kwok, A. O. L., Wong, D. M. L., Suen, M. H. P., Chen, W. T., \& Tse, D. M. W. (2009). Symptom burden and quality of life in end-stage renal disease: a study of 179 patients on dialysis and palliative care. Palliative Medicine, 23(2), 111-119. https://doi.org/10.1177/0269216308101099.

[34] Gordon, P., Doyle, J., Johansen, K. (2011): Postdialysis fatigue is associated with sedentary behavior. Clinical Nephrology; 75(5): 426-433. PMid:21543022.

[35] Horigan, A. E., Schneider, S. M., Docherty, S., \& Barroso, J. (2013). The experience and self-management of fatigue in hemodialysis patients. Nephrology Nursing Journal: Journal of The American Nephrology Nurses' Association, 40(2), 113. Retrieved from https://www.ncbi.nlm.nih.gov/pmc/articles/PMC3703392/.

[36] Chang, Y., Cheng, S.Y., Lin, M., Gau, F.Y., Chao, Y.C. (2010). The effectiveness of intradialytic leg ergometry exercise for improving sedentary life style and fatigue among patients with chronic kidney disease: a randomized clinical trial. International Journal of Nursing Studies, 47(11), 1383-8. https://doi.org/10.1016/j.ijnurstu.2010.05.002.

[37] Turkmen, K., Erdur, F. M., Guney, I., Gaipov, A., Turgut, F., Altintepe, L., Saglam M., Tonbul H., \& Abdel-Rahman, E. M. (2012). Sleep quality, depression, and quality of life in elderly hemodialysis patients. International Journal of Nephrology and Renovascular Disease, 5 , 135. https://doi.org/10.2147/IJNRD.S36493.

[38] Yaghmayi, F., Khalfi, E., Khost, N., \& Alavi, A. (2005). The relationship between self-concept dimensions of health status in patients treated with hemodialysis in medical science hospital in 2004. Pajoohandeh Journal, 1(6), 9-15.

[39] Finkelstein, F. O., Wuerth, D., Troidle, L. K., \& Finkelstein, S. H. (2008). Depression and end-stage renal disease: a therapeutic challenge. Kidney international, 74(7), 843-845. https://doi.org/10.1038/ki.2008.222.

[40] Reid, K.J., Baron, K.G., Lu, B., Naylor, E., Wolfe, L., Zee, PC. (2010). Aerobic exercise improves self-reported sleep and quality of life in older adults with insomnia. Sleep Medicine, 11(9), 934-40. https://doi.org/10.1016/j.sleep.2010.04.014.

[41] Akin, S., Mendi, B., Ozturk, B., Cinper, C., \& Durna, Z. (2014). Assessment of relationship between self-care and fatigue and loneliness in haemodialysis patients. Journal of Clinical Nursing, 23(5-6), 856-864. https://doi.org/10.1111/jocn.12248.

[42] Karadag, E., Kilic, S.P., Metin, O. (2013). Relationship between fatigue and social support in hemodialysis patients. Nursing \& Health Sciences, 15(2), 164-171. Retrieved from https://www.ncbi.nlm.nih.gov. https://doi.org/10.1111/nhs.12008.

[43] Bai, Y. L., Lai, L. Y., Lee, B. O., Chang, Y. Y., \& Chiou, C. P. (2015). The impact of depression on fatigue in patients with haemodialysis: a correlational study. Journal of Clinical Nursing, 24(13-14), 2014-22. https://doi.org/10.1111/jocn.12804. 